\title{
Safety evaluation of morphological changes in corneal endothelial cells induced by K-115 in cynomolgus monkeys
}

\author{
Eiji Wato', Kozo Omichi², Shigeki Yoneyama ${ }^{3}$, Mamoru Tanaka ${ }^{4}$, Masataka Kagawa ${ }^{1}$ \\ and Yukinori Amano' \\ ${ }^{1}$ Toxicology Group, Fuji Research Laboratories, Kowa Company, Ltd., 332-1 Ohno Shinden, \\ Fuji, Shizuoka 417-8650, Japan \\ ${ }^{2}$ Xenobiotics Group, Fuji Research Laboratories, Kowa Company, Ltd., 332-1 Ohno Shinden, \\ Fuji, Shizuoka 417-8650, Japan \\ ${ }^{3}$ Research Administration Department, Safety Research Center, Ina Research Inc., \\ 2148-188 Nishiminowa, Ina, Nagano 399-4501, Japan \\ ${ }^{4}$ Animal Research Department, Safety Research Center, Ina Research Inc., \\ 2148-188 Nishiminowa, Ina, Nagano 399-4501, Japan
}

(Received October 1, 2014; Accepted October 3, 2014)

\begin{abstract}
The present study was designed to evaluate the morphological changes in corneal endothelial cells (CECs), induced by K-115 ophthalmic solution in the ophthalmology, using a specular microscope. Unclear borders between CECs and slightly decreasing trends in corneal thicknesses were noted following ocular instillation of the K-115 ophthalmic solutions into cynomolgus monkeys. These changes were transient and disappeared within $24 \mathrm{hr}$ after instillation. In addition, no significant differences were noted in the degrees or frequencies of these lesions, between the single and 10-day repeated instillations, and no appreciable changes were noted in the number of CECs at $24 \mathrm{hr}$ after instillation. No significant structural changes were noted by histopathological examinations using light, transmission electron, and scanning electron microscopy. Similar changes were also noted following ocular instillation of Y-39983 ophthalmic solution at $0.25 \%$, with Rho-Associated, Coiled-Coil Containing Protein Kinase (ROCK) inhibitory effects, similar to the K-115 ophthalmic solution $2.0 \%$. Therefore, the changes were due to pharmacological effects of the K-115 ophthalmic solution. In conclusion, some morphological changes in CECs, following instillation with K-115, were considered to be of minimal toxicological significance because, 1) they were noted transiently after instillation, and CECs recovered by $24 \mathrm{hr}$ after instillation, 2) no enhancement by repeated instillation was noted, 3) no appreciable changes were noted in the corneal thickness or the number of CECs at $24 \mathrm{hr}$ after instillation, and 4) no significant structural changes were noted.
\end{abstract}

Key words: Morphological changes in CECs, Safety evaluation, K-115, Specular microscopy, Monkeys

\section{INTRODUCTION}

The corneal endothelial cells (CECs) are a single layer of flat hexagonal cells that border the posterior surface of the cornea, proximal to Descemet's membrane. The pump function and barrier function of the CECs are responsible for maintaining corneal thickness and transparency, by regulating stromal hydration (Dikstein and Maurice, 1972). Because the CECs show limited regenerative capacity, they gradually become depleted in cell number from wounding injuries, such as from trauma or other insults. A functional shortfall, by a decrease in the number of CECs is compensated for by the lateral expansion of remaining cells, but when this density is reduced below a critical level (approximately $400-700$ cells $/ \mathrm{mm}^{2}$ ), stromal edema occurs (Sumide et al., 2006).

In a 52-week ocular instillation toxicity study of K-115 in cynomolgus monkeys, morphological changes of the CECs were noted using a specular microscope (Topcon Corporation, Tokyo, Japan), though they were transient. Therefore, the present study was designed to evaluate the morphological changes in the CECs induced by K-115

Correspondence: Eiji Wato (E-mail: e-wato@kowa.co.jp) 
ophthalmic solution.

\section{MATERIALS AND METHODS}

\section{Chemicals}

K-115 ophthalmic solutions at $0.4 \%$, and $2.0 \%$, and a Y-39983 ophthalmic solution at $0.25 \%$ were manufactured at Kowa Company, Ltd. (Aichi, Japan). Ketamine hydrochloride (Ketamine Inj., 5\%, Fujita) was purchased from Fujita Pharmaceutical Co., Ltd. (Tokyo, Japan). Xylazine hydrochloride (Celactal ${ }^{\circledR}, 2 \%$ ) was purchased from Bayer (Leverkusen, Germany).

\section{Animals and housing conditions}

Female cynomolgus monkeys were purchased from Japan Laboratory Animals, Inc. (Tokyo, Japan). After quarantine and acclimatization, only healthy animals showing favorable body weight gain and good clinical signs were used for the study. The animals for each study were housed individually in stainless steel cages, in an animal room, under controlled conditions of $22-28^{\circ} \mathrm{C}$ temperature, $40-80 \%$ humidity, and ventilation at 15-23 times/hr, with $12 \mathrm{hr}$ illumination (lights on at 7 a.m. and lights off at 7 p.m.). Feed and sterilized tap water was available ad libitum. This study was conducted in compliance with the "Partial Amendments to the Law for the Humane Treatment and Management of Animals (Law No. 68, June 22, 2005, Japan)" and the "Guidance for Animal Care and Use (revised on Nov. 7, 2007)" of Ina Research Inc. (Nagano, Japan), and in accordance with the protocol reviewed by the Institutional Animal Care and Use Committee (IACUC) of Ina Research Inc., which is fully accredited by AAALAC International (Accreditation Unit No. 001107).

\section{Study designs}

\section{Experiment 1}

K-115 ophthalmic solutions $0.4 \%, 2.0 \%$ or $\mathrm{Y}-39983$ ophthalmic solution $0.25 \%$ were instilled once into the left eye of four female cynomolgus monkeys/group, in a volume of $20 \mu \mathrm{L}$, to evaluate the time course of morphological changes in the CECs. The right eye was left untreated (control). Observations of the morphological changes of the CECs at 1, 4, and $24 \mathrm{hr}$ after instillation, and measurements of the corneal thickness and the number of the CECs before instillation and at 1, 4, and $24 \mathrm{hr}$ after instillation, were performed, using a specular microscope.

\section{Experiment 2}

$\mathrm{K}-115$ ophthalmic solution $0.4 \%$ was instilled twice daily, while K-115 ophthalmic solution $2.0 \%$ or Y-39983 ophthalmic solution $0.25 \%$ were instilled four times daily (once on the last day of instillation, for all solutions), for 10 days, in a similar manner, using the same animals as used in Experiment 1, to evaluate the presence or absence of the enhancement by repeated instillations. Durations of 10 days were selected because the concentrations of $\mathrm{K}-115$ ophthalmic solutions in the cornea were expected to reach steady state after repeated instillation during this time period. Observations of the morphological changes of the CECs, and measurements of the corneal thickness and the number of the CECs, were performed at 1, 4, and $24 \mathrm{hr}$ after the last instillation, using a specular microscope.

\section{Experiment 3}

K-115 ophthalmic solutions $0.4 \%, 2.0 \%$ or Y-39983 ophthalmic solution $0.25 \%$ were instilled once into the left eyes of the two animals/group used in experiments 1 and 2 . The animals were necropsied at $1 \mathrm{hr}$ after instillation (corresponding to the time at which severe morphological changes of the CECs were noted in experiments 1 and 2), and the remaining two animals/group were necropsied 1 day before instillation (after recovery from the morphological changes of the CECs, in experiment 2). For the CECs, light microscopy, transmission electron microscopy, and scanning electron microscopy were used to evaluate the presence or absence of structural changes.

\section{Justification for selection of the concentrations, frequency, and dose volume}

To evaluate the morphological changes in the CECs noted in a 52-week ocular instillation toxicity study, in cynomolgus monkeys, K-115 ophthalmic solution $2.0 \%$, the highest concentration in the 52-week toxicity study, was selected. In addition, K-115 ophthalmic solution $0.4 \%$, the clinically used concentration, was selected. Y-39983 ophthalmic solution $0.25 \%$, the comparative control with Rho-Associated, Coiled-Coil Containing Protein Kinase (ROCK) inhibitory effects, similar to the K-115 ophthalmic solution $2.0 \%$, was selected. For the frequency of K-115 ophthalmic solution $0.4 \%$, used in experiment 2, the solution was instilled twice daily, the same as the clinical use frequency. For the frequency of K-115 ophthalmic solutions $2.0 \%$ and Y-39983 ophthalmic solution $0.25 \%$, as in experiment 2 , instillation four times per day was selected, which was the same frequency used in the 52-week toxicity study. The dose volume of $20 \mu \mathrm{L} /$ dose/eye was considered to be appropriate for instillation into the eyes of monkeys. 
Safety evaluation of morphological changes in the CECs

\section{Observation of the morphological changes in CECs, measurements of the corneal thickness, and the number of the CECs}

The animals were anesthetized with ketamine hydrochloride $(0.1-0.4 \mathrm{~mL} / \mathrm{kg})$ and xylazine hydrochloride $(0.05-0.1 \mathrm{~mL} / \mathrm{kg})$ by intramuscular injection. Photographs of CECs were taken by a specular microscope (Topcon Corporation) to observe the morphological changes of the CECs. The corneal thickness and the number of CECs were also determined using a specular microscope, and the mean values were calculated. Physiological saline was instilled during and after examinations to prevent corneal drying caused by anesthesia.

\section{Histopathology}

The removed eyes were promptly immersed in $0.1 \mathrm{~mol} / \mathrm{L}$ ice-chilled phosphate-buffered $2.5 \%$ glutaraldehyde fixative for approximately $1 \mathrm{hr}$. Approximately $0.2-$ $0.3 \mathrm{~mL}$ of the same fixative was injected into the removed eye to replace the anterior chamber humor. Then, the eyes were re-immersed in an ice-chilled $0.1 \mathrm{~mol} / \mathrm{L}$ phosphatebuffered $2.5 \%$ glutaraldehyde fixative for approximately $1 \mathrm{hr}$. After fixation, the cornea was cut into three pieces to prepare tissue samples for light microscopy, transmission electron microscopy, and scanning electron microscopy.

\section{Light microscopy}

The tissue samples for light microscopy were fixed in $10 \mathrm{vol} \%$ neutral buffered formalin, routinely processed, and stained with hematoxylin and eosin (HE). All specimens were examined by light microscopy.

\section{Transmission electron microscopy}

The tissue samples for transmission electron microscopy were cut into small pieces, prefixed in a $0.1 \mathrm{~mol} / \mathrm{L}$ phosphate-buffered $2.5 \%$ glutaraldehyde fixative, postfixed in a $1 \%$ osmium tetroxide solution, and embedded in epoxy resin to prepare blocks for sectioning. From all animal tissues, ultrathin sections were prepared from the resin-embedded blocks, double stained with a $2 \%$ aqueous solution of uranyl acetate and $0.4 \%$ lead citrate, and examined under a transmission electron microscope.

\section{Scanning electron microscopy}

The tissue samples prepared for scanning electron microscopy were immersed in an ice-chilled $0.1 \mathrm{~mol} / \mathrm{L}$ phosphate-buffered $2.5 \%$ glutaraldehyde fixative, for approximately $30 \mathrm{~min}$, rinsed with $0.1 \mathrm{~mol} / \mathrm{L}$ phosphate buffer, and immersed in an ice-chilled $1 \%$ osmium tetroxide solution, for approximately $2 \mathrm{hr}$. These samples were then rinsed with $0.1 \mathrm{~mol} / \mathrm{L}$ phosphate buffer, dehydrat- ed with ethanol, and immersed in t-butyl alcohol. Then, the samples were routinely freeze-dried and coated with osmium. The specimens from all animals were examined using a scanning electron microscope.

\section{Statistical analysis}

Mean group values and standard deviations were calculated, based on the numerical data obtained from each group. Statistical analysis for significant differences was not conducted.

\section{RESULTS}

\section{Experiment 1}

For observation of the morphological changes in CECs, severely unclear borders between cells were noted in the treated eye (left eye) of all animals in all groups at $1 \mathrm{hr}$ after instillation, of two animals in the K-115 ophthalmic solution $2.0 \%$ treated group and all animals in the Y-39983 ophthalmic solution $0.25 \%$ treated group at $4 \mathrm{hr}$ after instillation. Slightly or moderately unclear borders between cells were noted in the treated eye (left eye) of all animals in the K-115 ophthalmic solution $0.4 \%$ treated group and two animals in the K-115 ophthalmic solution $2.0 \%$ treated group at $4 \mathrm{hr}$ after instillation. No appreciable changes were noted in any treated eye (left eye) at 24 $\mathrm{hr}$ after instillation, and in any untreated eye (right eye) at any time point (Table 1 and Fig. 1).

A slightly decreasing trend of corneal thickness was noted in the treated eye (left eye) in all groups at 1 and $4 \mathrm{hr}$ after instillation, however, this change recovered at $24 \mathrm{hr}$ after instillation. In addition, no appreciable changes were noted in any untreated eye (right eye) (Table 2).

The number of CECs could not be calculated owing to severely or moderately unclear borders between cells in the treated eyes (left eye) of all animals in all groups at $1 \mathrm{hr}$ after instillation, of three animals in the K-115 ophthalmic solution $2.0 \%$ treated group and all animals in the Y-39983 ophthalmic solution $0.25 \%$ treated group at $4 \mathrm{hr}$ after instillation. No appreciable changes were noted in any treated eye (left eye) of animals at $24 \mathrm{hr}$ after instillation, or in any untreated eye (right eye) at any time point (Table 3).

\section{Experiment 2}

For observation of the morphological changes in CECs, severely unclear borders between cells were noted in the treated eyes (left eye) of all animals in all groups at $1 \mathrm{hr}$ after instillation, and of three animals in the K-115 ophthalmic solution $0.4 \%$ treated group and all animals in the K-115 ophthalmic solution $0.4 \%$ and the Y-39983 


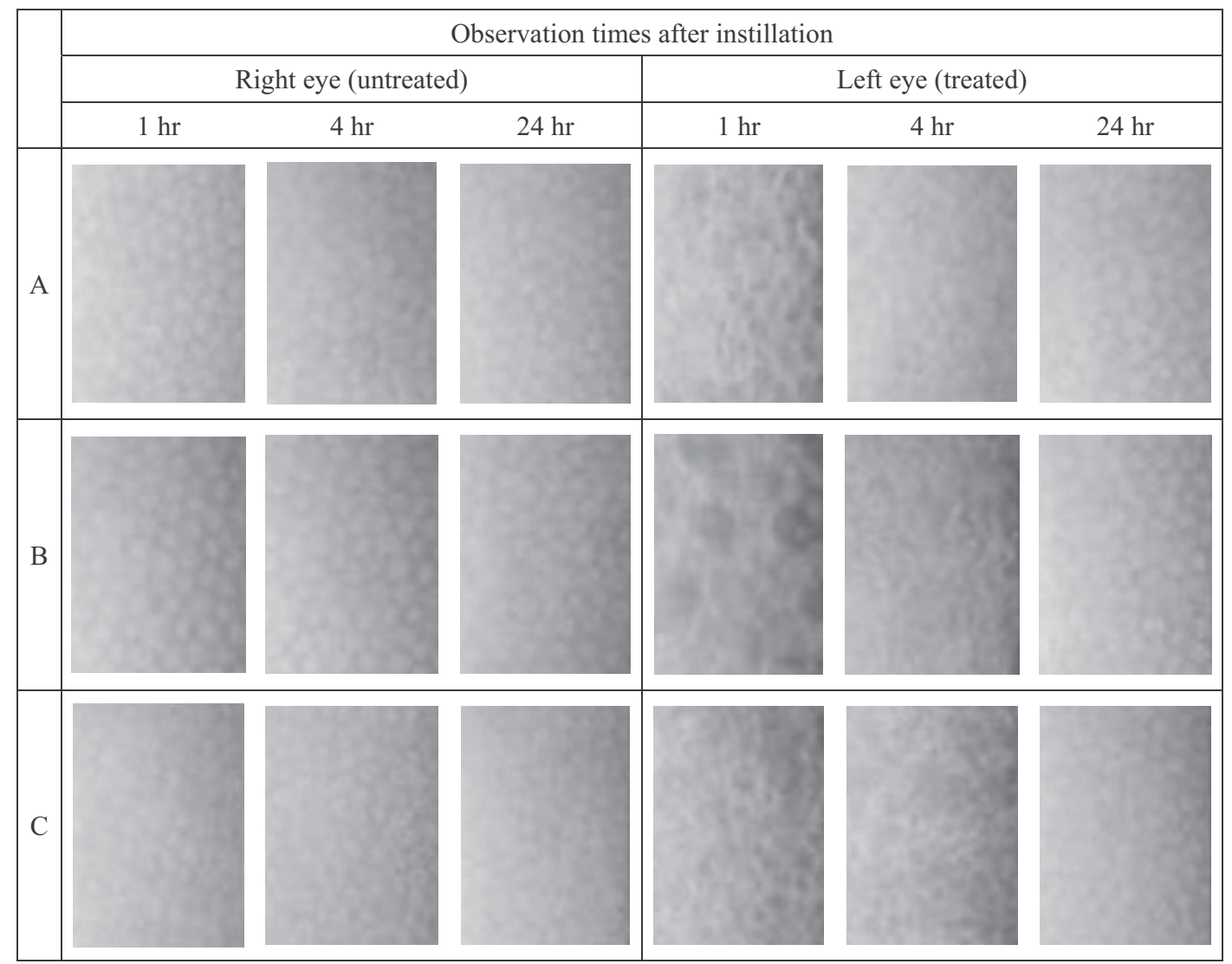

Fig. 1. Morphological changes in the CECs (from Experiment 1) (A): K-115 ophthalmic solution 0.4\%, (B): K-115 ophthalmic solution $2.0 \%$ and $(\mathrm{C})$ : Y-39983 ophthalmic solution $0.25 \%$, were instilled once into the left eye of cynomolgus monkeys, in a volume of $20 \mu \mathrm{L}$ each. The right eye of each animal was left untreated. Photographs of CECs were taken by a specular microscope at 1, 4, and $24 \mathrm{hr}$ after instillation. Severely unclear borders between cells in the treated eye (left eye) are noted in all groups at $1 \mathrm{hr}$ after instillation, in the K-115 ophthalmic solution 2.0\% treated group and the Y-39983 ophthalmic solution $0.25 \%$ treated group at $4 \mathrm{hr}$ after instillation. Slightly unclear borders between cells in the treated eyes (left eye) are noted in the K-115 ophthalmic solution $0.4 \%$ treated group at $4 \mathrm{hr}$ after instillation. No unclear borders between cells are noted in any groups at $24 \mathrm{hr}$ after instillation.

ophthalmic solution $0.25 \%$ treated groups at $4 \mathrm{hr}$ after instillation. Moderately unclear borders between cells were noted in the treated eye (left eye) of one animal in the K-115 ophthalmic solution $0.4 \%$ treated group at $4 \mathrm{hr}$ after instillation. No appreciable changes were noted in any treated eye (left eye) at $24 \mathrm{hr}$ after instillation, and in any untreated eye (right eye) at any time point (Table 4 and Fig. 2).

A slightly decreasing trend of the corneal thickness was noted in the treated eye (left eye) in the K-115 ophthalmic solutions 0.4 and $2.0 \%$ treated groups at $1 \mathrm{hr}$ after instillation and in all groups at $4 \mathrm{hr}$ after instillation, however, this change was not noted at $24 \mathrm{hr}$ after instillation. In addition, no appreciable changes were noted in any untreated eye (right eye) (Table 5).

The number of CECs could not be calculated owing to severely or moderately unclear borders between cells in the treated eyes (left eye) of all animals in all groups at 1 and $4 \mathrm{hr}$ after instillation. No appreciable changes were noted in any treated eye (left eye) at $24 \mathrm{hr}$ after instillation, and in any untreated eye (right eye) at any time point (Table 6).

\section{Experiment 3}

For light microscopy, no histopathological changes were noted in the CECs in either eye of any animal in any group (Table 7).

For transmission electron microscopy, no ultramicro- 
Safety evaluation of morphological changes in the CECs

Table 1. Morphological changes in CECs as assessed by specular microscopy (from Experiment 1).

\begin{tabular}{|c|c|c|c|c|c|c|c|c|c|c|c|c|c|c|c|c|c|c|c|c|c|c|c|c|}
\hline \multirow{3}{*}{$\begin{array}{l}\text { Group } \\
\text { Eye }\end{array}$} & & \multicolumn{16}{|c|}{ K-115 ophthalmic solution } & \multirow{2}{*}{\multicolumn{7}{|c|}{$\begin{array}{c}\text { Y-39983 ophthalmic solution } \\
0.25 \%\end{array}$}} \\
\hline & & \multicolumn{8}{|c|}{$0.4 \%$} & \multicolumn{8}{|c|}{$2.0 \%$} & & & & & & & \\
\hline & & \multicolumn{4}{|c|}{$\mathrm{R}$} & \multicolumn{4}{|c|}{$\mathrm{L}$} & \multicolumn{4}{|c|}{$\mathrm{R}$} & \multicolumn{4}{|c|}{$\mathrm{L}$} & \multicolumn{4}{|c|}{$\mathrm{R}$} & \multicolumn{3}{|c|}{$\mathrm{L}$} \\
\hline $\mathrm{N}$ & & \multicolumn{4}{|c|}{4} & \multicolumn{4}{|c|}{4} & \multicolumn{4}{|c|}{4} & \multicolumn{4}{|c|}{4} & \multicolumn{4}{|c|}{4} & \multicolumn{3}{|c|}{4} \\
\hline Time (hr) & & Pre & 1 & 4 & 24 & Pre & 1 & 4 & 24 & Pre & 1 & 4 & 24 & Pre & 1 & 4 & 24 & Pre & 1 & 4 & 24 & Pre & 1 & 4 \\
\hline & - & 4 & 4 & 4 & 4 & 4 & & & 4 & 4 & 4 & 4 & 4 & 4 & & & 4 & 4 & 4 & 4 & 4 & 4 & & \\
\hline Unclear & + & & & & & & & 4 & & & & & & & & 1 & & & & & & & & \\
\hline borders & ++ & & & & & & & & & & & & & & & 1 & & & & & & & & \\
\hline & +++ & & & & & & 4 & & & & & & & & 4 & 2 & & & & & & & 4 & 4 \\
\hline
\end{tabular}

R: Right eye (untreated) L: Left eye (treated) N: The number of eyes examined

Pre: Before instillation Time: Observation times after instillation

Unclear borders: Unclear borders between CECs [-: None, +: Slight, ++: Moderate, +++: Severe]

Table 2. Measurements of corneal thickness (from Experiment 1).

\begin{tabular}{|c|c|c|c|c|c|c|}
\hline \multirow{3}{*}{$\begin{array}{l}\text { Group } \\
\text { Eye }\end{array}$} & \multicolumn{4}{|c|}{ K-115 ophthalmic solution } & \multirow{2}{*}{\multicolumn{2}{|c|}{$\begin{array}{c}\text { Y-39983 ophthalmic solution } \\
0.25 \%\end{array}$}} \\
\hline & \multicolumn{2}{|c|}{$0.4 \%$} & \multicolumn{2}{|c|}{$2.0 \%$} & & \\
\hline & $\mathrm{R}$ & $\mathrm{L}$ & $\mathrm{R}$ & $\mathrm{L}$ & $\mathrm{R}$ & $\mathrm{L}$ \\
\hline $\mathrm{N}$ & 4 & 4 & 4 & 4 & 4 & 4 \\
\hline Pre & $0.433 \pm 0.021$ & $0.432 \pm 0.023$ & $0.434 \pm 0.022$ & $0.434 \pm 0.023$ & $0.433 \pm 0.025$ & $0.436 \pm 0.024$ \\
\hline $1 \mathrm{hr}$ & $0.430 \pm 0.022$ & $0.421 \pm 0.025$ & $0.433 \pm 0.023$ & $0.414 \pm 0.022$ & $0.435 \pm 0.026$ & $0.425 \pm 0.020$ \\
\hline $4 \mathrm{hr}$ & $0.432 \pm 0.024$ & $0.419 \pm 0.017$ & $0.438 \pm 0.025$ & $0.408 \pm 0.029$ & $0.436 \pm 0.027$ & $0.402 \pm 0.029$ \\
\hline $24 \mathrm{hr}$ & $0.430 \pm 0.022$ & $0.433 \pm 0.021$ & $0.433 \pm 0.021$ & $0.434 \pm 0.021$ & $0.435 \pm 0.027$ & $0.434 \pm 0.029$ \\
\hline
\end{tabular}

Values are shown as mean $(\mathrm{mm}) \pm$ S.D.

R: Right eye (untreated) L: Left eye (treated) N: The number of eyes examined

Pre: Before instillation $1(4,24) \mathrm{hr}: 1(4,24) \mathrm{hr}$ after instillation

Table 3. Measurements of the number of CECs (from Experiment 1).

\begin{tabular}{lcccccc}
\hline \multirow{2}{*}{ Group } & \multicolumn{3}{c}{ K-115 ophthalmic solution } & \multicolumn{2}{c}{ Y-39983 ophthalmic solution } \\
\cline { 2 - 5 } & \multicolumn{2}{c}{$0.4 \%$} & \multicolumn{2}{c}{$2.0 \%$} & \multicolumn{2}{c}{$0.25 \%$} \\
\hline Eye & $\mathrm{R}$ & $\mathrm{L}$ & $\mathrm{R}$ & $\mathrm{L}$ & $\mathrm{L}$ \\
\hline Pre & $3397 \pm 416[4]$ & $3353 \pm 408[4]$ & $3322 \pm 209[4]$ & $3275 \pm 190[4]$ & $3402 \pm 467[4]$ & $3296 \pm 552[4]$ \\
$1 \mathrm{hr}$ & $3449 \pm 449[4]$ & $\mathrm{NC}[0] \#$ & $3364 \pm 153[4]$ & $\mathrm{NC}[0] \#$ & $3522 \pm 496[4]$ & NC[0]\# \\
$4 \mathrm{hr}$ & $3406 \pm 409[4]$ & $3302 \pm 389[4]$ & $3307 \pm 124[4]$ & $3108[1] \#$ & $3339 \pm 535[4]$ & NC[0]\# \\
$24 \mathrm{hr}$ & $3409 \pm 396[4]$ & $3313 \pm 365[4]$ & $3307 \pm 120[4]$ & $3210 \pm 91[4]$ & $3373 \pm 483[4]$ & $3389 \pm 483[4]$ \\
\hline
\end{tabular}

Values are shown as mean (cells $\left./ \mathrm{mm}^{2}\right) \pm$ S.D. [The number of eyes calculated]

\#: Because there are animals for which CECs could not be counted.

R: Right eye (untreated) L: Left eye (treated) NC: Not calculated

Pre: Before instillation $1(4,24) \mathrm{hr}: 1(4,24) \mathrm{hr}$ after instillation

Table 4. Morphological changes in CECs noted by specular microscopy (from Experiment 2).

\begin{tabular}{|c|c|c|c|c|c|c|c|c|c|c|c|c|c|c|c|c|c|c|c|}
\hline \multirow{3}{*}{$\begin{array}{l}\text { Group } \\
\text { Eye }\end{array}$} & & \multicolumn{12}{|c|}{ K-115 ophthalmic solution } & \multirow{2}{*}{\multicolumn{6}{|c|}{$\begin{array}{c}\text { Y-39983 ophthalmic solution } \\
0.25 \%\end{array}$}} \\
\hline & & \multicolumn{6}{|c|}{$0.4 \%$} & \multicolumn{6}{|c|}{$2.0 \%$} & & & & & & \\
\hline & & \multicolumn{3}{|c|}{$\mathrm{R}$} & \multicolumn{3}{|c|}{$\mathrm{L}$} & \multicolumn{3}{|c|}{$\mathrm{R}$} & \multicolumn{3}{|c|}{$\mathrm{L}$} & \multicolumn{3}{|c|}{$\mathrm{R}$} & \multicolumn{3}{|c|}{$\mathrm{L}$} \\
\hline $\mathrm{N}$ & & \multicolumn{3}{|c|}{4} & \multicolumn{3}{|c|}{4} & \multicolumn{3}{|c|}{4} & \multicolumn{3}{|c|}{4} & \multicolumn{3}{|c|}{4} & \multicolumn{3}{|c|}{4} \\
\hline Time (hr) & & 1 & 4 & 24 & 1 & 4 & 24 & 1 & 4 & 24 & 1 & 4 & 24 & 1 & 4 & 24 & 1 & 4 & 24 \\
\hline \multirow{4}{*}{$\begin{array}{l}\text { Unclear } \\
\text { borders }\end{array}$} & - & 4 & 4 & 4 & & & & 4 & 4 & 4 & & & & 4 & 4 & 4 & & & \\
\hline & + & & & & & & & & & & & & & & & & & & \\
\hline & ++ & & & & & 1 & & & & & & & & & & & & & \\
\hline & +++ & & & & 4 & 3 & 0 & & & & 4 & 4 & 0 & & & & 4 & 4 & 0 \\
\hline
\end{tabular}

R: Right eye (untreated) L: Left eye (treated) N: The number of eyes examined

Time: Observation times after instillation

Unclear borders: Unclear borders between CECs [-: None, +: Slight, ++: Moderate, +++: Severe] 


\section{E. Wato et al.}

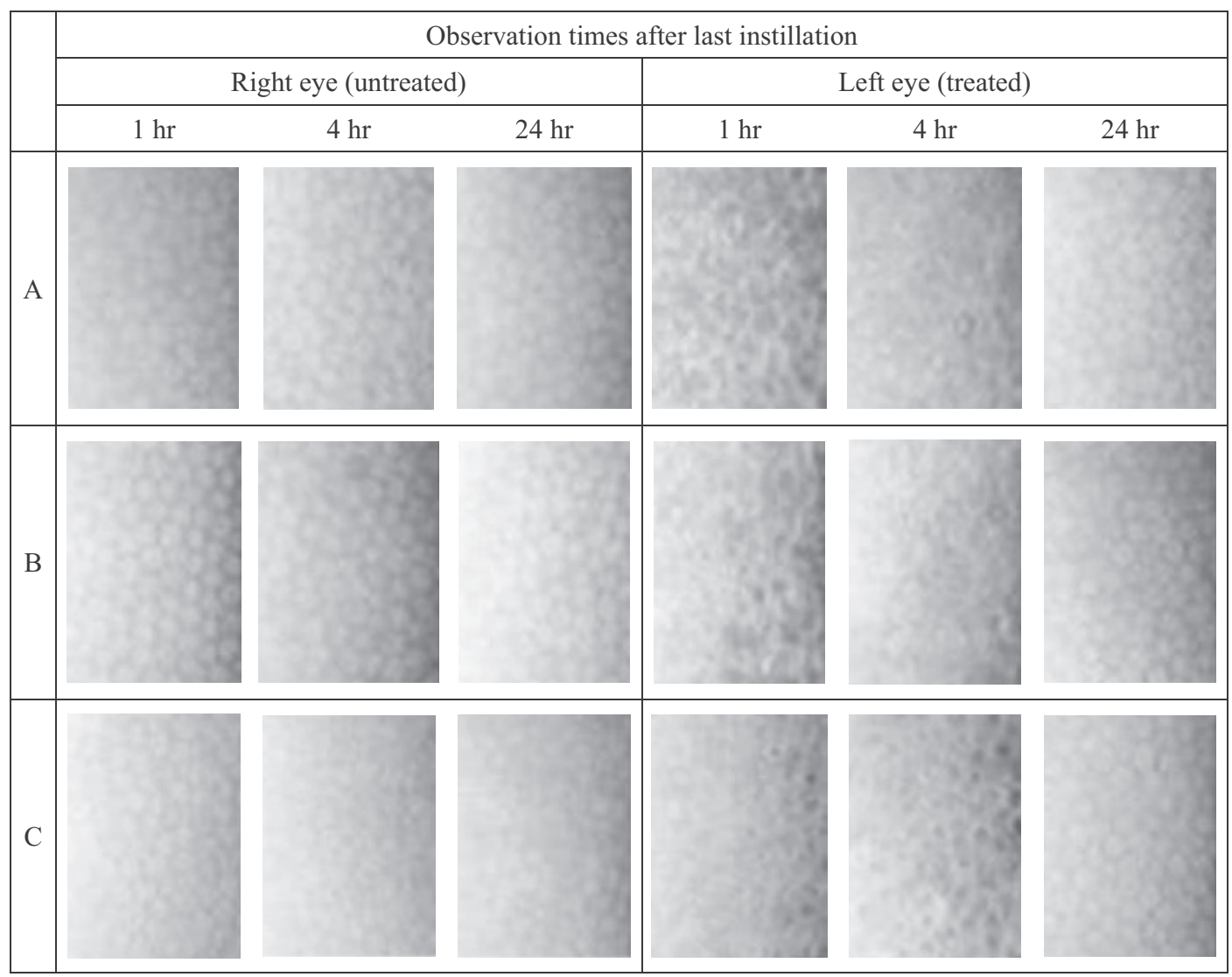

Fig. 2. Morphological changes in the CECs (from Experiment 2) (A): The K-115 ophthalmic solution $0.4 \%$ was instilled twice daily, (B): the K-115 ophthalmic solution $2.0 \%$ and (C): Y-39983 ophthalmic solution $0.25 \%$ were instilled, four times daily (and once on the last day of instillation, for all ophthalmic solutions), for 10 days, into the left eye of cynomolgus monkeys, in a volume of $20 \mu \mathrm{L}$. The right eye of each animal was left untreated. Photographs of CECs are from a specular microscope at 1, 4, and $24 \mathrm{hr}$ after instillation. Severely unclear borders between cells in the treated eyes (left eye) in all groups at 1 and $4 \mathrm{hr}$ after instillation are noted. No unclear borders between cells are noted in any groups at $24 \mathrm{hr}$ after instillation.

Table 5. Measurements of corneal thickness (from Experiment 2).

\begin{tabular}{|c|c|c|c|c|c|c|}
\hline \multirow{3}{*}{$\begin{array}{l}\text { Group } \\
\text { Eye }\end{array}$} & \multicolumn{4}{|c|}{ K-115 ophthalmic solution } & \multirow{2}{*}{\multicolumn{2}{|c|}{$\begin{array}{c}\text { Y-39983 ophthalmic solution } \\
0.25 \%\end{array}$}} \\
\hline & \multicolumn{2}{|c|}{$0.4 \%$} & \multicolumn{2}{|c|}{$2.0 \%$} & & \\
\hline & $\mathrm{R}$ & $\mathrm{L}$ & $\mathrm{R}$ & $\mathrm{L}$ & $\mathrm{R}$ & $\mathrm{L}$ \\
\hline $\mathrm{N}$ & 4 & 4 & 4 & 4 & 4 & 4 \\
\hline $1 \mathrm{hr}$ & $0.433 \pm 0.022$ & $0.424 \pm 0.020$ & $0.439 \pm 0.021$ & $0.427 \pm 0.021$ & $0.443 \pm 0.030$ & $0.442 \pm 0.029$ \\
\hline $4 \mathrm{hr}$ & $0.434 \pm 0.028$ & $0.423 \pm 0.025$ & $0.441 \pm 0.020$ & $0.421 \pm 0.024$ & $0.436 \pm 0.030$ & $0.422 \pm 0.031$ \\
\hline $24 \mathrm{hr}$ & $0.435 \pm 0.026$ & $0.435 \pm 0.025$ & $0.436 \pm 0.030$ & $0.437 \pm 0.023$ & $0.438 \pm 0.030$ & $0.441 \pm 0.029$ \\
\hline
\end{tabular}

Values are shown as mean $(\mathrm{mm}) \pm$ S.D.

R: Right eye (untreated) L: Left eye (treated) N: The number of eyes examined $1(4,24) \mathrm{hr}: 1(4,24) \mathrm{hr}$ after instillation

morphological abnormalities were noted in the nucleus, organelle, or other organelles in the CECs, in either eye of any animal in any group (Table 8 ).

For scanning electron microscopy, slightly enlarged
CECs were sporadically noted in the treated eye (left eye) of one animal in the K-115 ophthalmic solution $2.0 \%$ treated group. No abnormal CECs were noted in the other animals in this group, or in the other groups (Table 9). 
Safety evaluation of morphological changes in the CECs

Table 6. Measurements of the number of CECs (from Experiment 2).

\begin{tabular}{|c|c|c|c|c|c|c|}
\hline \multirow{3}{*}{$\begin{array}{l}\text { Group } \\
\text { Eye }\end{array}$} & \multicolumn{4}{|c|}{ K-115 ophthalmic solution } & \multirow{2}{*}{\multicolumn{2}{|c|}{$\begin{array}{c}\text { Y-39983 ophthalmic solution } \\
0.25 \%\end{array}$}} \\
\hline & \multicolumn{2}{|c|}{$0.4 \%$} & \multicolumn{2}{|c|}{$2.0 \%$} & & \\
\hline & $\mathrm{R}$ & $\mathrm{L}$ & $\mathrm{R}$ & $\mathrm{L}$ & $\mathrm{R}$ & $\mathrm{L}$ \\
\hline $1 \mathrm{hr}$ & $3328 \pm 464[4]$ & $\mathrm{NC}[0] \#$ & $3311 \pm 175[4]$ & $\mathrm{NC}[0] \#$ & $3397 \pm 426[4]$ & $\mathrm{NC}[0] \#$ \\
\hline $4 \mathrm{hr}$ & $3445 \pm 500[4]$ & $\mathrm{NC}[0] \#$ & $3295 \pm 113[4]$ & $\mathrm{NC}[0] \#$ & $3328 \pm 396[4]$ & NC $[0] \#$ \\
\hline $24 \mathrm{hr}$ & $3356 \pm 370[4]$ & $3350 \pm 426[4]$ & $3311 \pm 131[4]$ & $3281 \pm 100[4]$ & $3396 \pm 549[4]$ & $3279 \pm 459[4]$ \\
\hline
\end{tabular}

Values are shown as mean (cells $\left./ \mathrm{mm}^{2}\right) \pm$ S.D. [Number of eyes calculated]

\#: Because there are animals for which CECs could not be counted.

R: Right eye (untreated) L: Left eye (treated) NC: Not calculated

$1(4,24)$ hr: $1(4,24) \mathrm{hr}$ after instillation

Table 7. Light microscopy results (from Experiment 3).

\begin{tabular}{|c|c|c|c|c|c|c|c|c|c|c|c|c|c|}
\hline \multirow{4}{*}{$\begin{array}{l}\text { Organ } \\
\text { Findings }\end{array}$} & \multirow{4}{*}{$\begin{array}{c}\text { Group } \\
\text { NT } \\
\text { Eye }\end{array}$} & \multicolumn{8}{|c|}{ K-115 ophthalmic solution } & \multirow{2}{*}{\multicolumn{4}{|c|}{$\begin{array}{c}\text { Y-39983 ophthalmic solution } \\
0.25 \%\end{array}$}} \\
\hline & & \multicolumn{4}{|c|}{$0.4 \%$} & \multicolumn{4}{|c|}{$2.0 \%$} & & & & \\
\hline & & \multicolumn{2}{|c|}{ Pre } & \multicolumn{2}{|c|}{$1 \mathrm{hr}$} & \multicolumn{2}{|c|}{ Pre } & \multicolumn{2}{|c|}{$1 \mathrm{hr}$} & \multicolumn{2}{|c|}{ Pre } & \multicolumn{2}{|c|}{$1 \mathrm{hr}$} \\
\hline & & $\mathrm{R}$ & $\mathrm{L}$ & $\mathrm{R}$ & $\mathrm{L}$ & $\mathrm{R}$ & $\mathrm{L}$ & $\mathrm{R}$ & $\mathrm{L}$ & $\mathrm{R}$ & $\mathrm{L}$ & $\mathrm{R}$ & $\mathrm{L}$ \\
\hline CESs[2] & - & 2 & 2 & 2 & 2 & 2 & 2 & 2 & 2 & 2 & 2 & 2 & 2 \\
\hline
\end{tabular}

NT: Necropsy time Pre: 1 day before instillation $1 \mathrm{hr}: 1 \mathrm{hr}$ after instillation

R: Right eye (untreated) L: Left eye (treated) Brackets, [ ]: Number of eyes examined

-: None/Negative

Table 8. Transmission electron microscopy results (from Experiment 3).

\begin{tabular}{|c|c|c|c|c|c|c|c|c|c|c|c|c|c|}
\hline \multirow{4}{*}{$\begin{array}{l}\text { Organ } \\
\text { Findings }\end{array}$} & \multirow{4}{*}{$\begin{array}{c}\text { Group } \\
\text { NT } \\
\text { Eye }\end{array}$} & \multicolumn{8}{|c|}{ K-115 ophthalmic solution } & \multirow{2}{*}{\multicolumn{4}{|c|}{$\begin{array}{c}\text { Y-39983 ophthalmic solution } \\
0.25 \%\end{array}$}} \\
\hline & & \multicolumn{4}{|c|}{$0.4 \%$} & \multicolumn{4}{|c|}{$2.0 \%$} & & & & \\
\hline & & & & & & & & & & & & & \\
\hline & & $\mathrm{R}$ & $\mathrm{L}$ & $\mathrm{R}$ & $\mathrm{L}$ & $\mathrm{R}$ & $\mathrm{L}$ & $\mathrm{R}$ & $\mathrm{L}$ & $\mathrm{R}$ & $\mathrm{L}$ & $\mathrm{R}$ & $\mathrm{L}$ \\
\hline CECs[2] & - & 2 & 2 & 2 & 2 & 2 & 2 & 2 & 2 & 2 & 2 & 2 & 2 \\
\hline
\end{tabular}

NT: Necropsy time Pre: 1 day before instillation $1 \mathrm{hr}: 1 \mathrm{hr}$ after instillation

R: Right eye (untreated) L: Left eye (treated) Brackets, [ ]: The number of eyes examined

-: None/Negative

Table 9. Scanning electron microscopy results (from Experiment 3).

\begin{tabular}{|c|c|c|c|c|c|c|c|c|c|c|c|c|c|}
\hline \multirow{4}{*}{$\begin{array}{l}\text { Organ } \\
\text { Findings }\end{array}$} & \multirow{4}{*}{$\begin{array}{c}\text { Group } \\
\text { NT } \\
\text { Eye }\end{array}$} & \multicolumn{8}{|c|}{ K-115 ophthalmic solution } & \multirow{2}{*}{\multicolumn{4}{|c|}{$\begin{array}{c}\text { Y-39983 ophthalmic solution } \\
0.25 \%\end{array}$}} \\
\hline & & \multicolumn{4}{|c|}{$0.4 \%$} & \multicolumn{4}{|c|}{$2.0 \%$} & & & & \\
\hline & & \multicolumn{2}{|c|}{ Pre } & \multicolumn{2}{|c|}{$1 \mathrm{hr}$} & \multicolumn{2}{|c|}{ Pre } & \multicolumn{2}{|c|}{$1 \mathrm{hr}$} & \multicolumn{2}{|c|}{ Pre } & \multicolumn{2}{|c|}{$1 \mathrm{hr}$} \\
\hline & & $\mathrm{R}$ & $\mathrm{L}$ & $\mathrm{R}$ & $\mathrm{L}$ & $\mathrm{R}$ & $\mathrm{L}$ & $\mathrm{R}$ & $\mathrm{L}$ & $\mathrm{R}$ & $\mathrm{L}$ & $\mathrm{R}$ & $\mathrm{L}$ \\
\hline CECs[2] & & & & & & & & & & & & & \\
\hline Enlarged endothelial & - & 2 & 2 & 2 & 2 & 2 & 2 & 2 & 1 & 2 & 2 & 2 & 2 \\
\hline cell, scattered, slight & $\mathrm{P}$ & & & & & & & & 1 & & & & \\
\hline
\end{tabular}

NT: Necropsy time Pre: 1 day before instillation $1 \mathrm{hr}: 1 \mathrm{hr}$ after instillation

R: Right eye (untreated) L: Left eye (treated) Brackets, [ ]: The number of eyes examined

-: None/Negative P: Present

\section{DISCUSSION}

$\mathrm{K}-115$ ophthalmic solution is a therapeutic drug for glaucoma and ocular hypertension that has a different mechanism of action from the existing drugs for glauco$\mathrm{ma}$, and has been demonstrated to lower intraocular pres- sure (IOP), by facilitating aqueous outflow, using major pathways via the trabecular meshwork and Schlemm's canal, through its ROCK inhibitory activity. In a 52-week ocular instillation toxicity study of K-115 in cynomolgus monkeys, transient morphological changes in the CECs were noted, using a specular microscope. Therefore, the 
present study was designed to evaluate the morphological changes in CECs, induced by K-115 ophthalmic solution.

Unclear borders between CECs, and a slightly decreasing corneal thickness were noted at 1 and $4 \mathrm{hr}$ after single ocular instillation of the K-115 ophthalmic solutions into cynomolgus monkeys (Experiment 1). These changes were transient and disappeared within $24 \mathrm{hr}$ after instillation, and no enhancement by repeated instillation was noted (Experiment 2). Similar changes were also noted following ocular instillation of Y-39983 ophthalmic solution, which is a ROCK inhibitor. Therefore, these changes could be caused through the pharmacological ROCK inhibitory effects of K-115 ophthalmic solution.

A specular microscope, used in the present study, makes it possible to photograph the CECs by receiving the reflected light from the surface of CECs (specular reflection) (Bourne and Mclaren, 2004). Owing to the flat surfaces of CECs, photographs were taken in bright areas, because of the high light-receiving efficiency, as the light was reflected along the optical axis (at the same angle of incidence) of the optical receiver of the apparatus. For uneven surfaces as seen at interfaces between CECs, photographs were taken in dark areas, because of the low light-receiving efficiency, as the light was reflected away from the optical axis (at the different angle of incidence). Unclear borders between CECs treated with K-115 ophthalmic solution were marked by reversed light and dark areas in the photographs of CECs. This result suggested that the flat surfaces of CECs changed to the uneven type surface. It has been reported that ROCK inhibitor blocks actin stress fiber (ASF) formation and focal adhesion (FA) (Honjo et al., 2001), which are principal structural components in the generation of intracellular pre-tension, and cell stiffness (Leung et al., 1996; Prasain and Stevens, 2009). Both play crucial roles in controlling the three-dimensional morphology of cells (Nagayama and Matsumoto, 2008). The disruption of ASF causes decreases in the elastic properties of the cells and cell swelling (increase in cell height) (Nagayama and Matsumoto, 2008). Therefore, the appearance of unclear borders between CECs may be caused by reflected light, away from the optical axis of the specular microscope, because the CECs may have swelled by the inhibition of ASFs formation caused by the pharmacological ROCK inhibitory effect of K-115 ophthalmic solution.

Corneal thickness is maintained by pump function and barrier function of the $\mathrm{CECs}$, by regulating stromal hydration (Dikstein and Maurice, 1972). The $\mathrm{Na}^{+}-/ \mathrm{K}^{+}$-dependent ATPase, expressed in the basolateral membrane of corneal endothelial cells, is primarily responsible for the pump function of the corneal endothelium, which sus- tains a constant flow of water out of the stroma (Hatou et al., 2010). Y-27632, which is a ROCK inhibitor, is known to increase pump function of human corneal endothelial cells (Bi et al., 2013). It has also been reported that Clostridium botulinum exoenzyme C3 transferase, an inhibitor of the small GTP-binding protein RhoA, caused ASF/FA disassembly and enhanced endothelial barrier function by reorganizing F-actin and phosphotyrosinecontaining proteins to a thin band that colocalized with $\beta$-catenin-containing cell-cell junctions, reducing the size of the paracellular space (Carbajal and Schaeffer, 1999). Therefore, a slightly decreased corneal thickness could be caused by increased pump function and barrier function of the CECs, through the pharmacological effect (ROCK inhibitory effect) of K-115 ophthalmic solution. In addition, this change was considered to have minimal toxicological significance because the change was slight and transient, and returned to normal values before the start of instillation within $24 \mathrm{hr}$ after instillation into cynomolgus monkeys, for 52 weeks (data not shown).

In Experiment 3, slightly enlarged CECs were sporadically noted, using scanning electron microscopy, in the treated eye (left eye) of one animal in the K-115 ophthalmic solution $2.0 \%$ treated group. However, this change was considered to be of minimal toxicological significance because it was slight and reversible, and was not a lateral expansion of remaining cells, which were noted to compensate for the functional shortfall by a decrease in the number of CECs. In addition, no histopathological changes, using light microscopy, and no ultramicro morphological abnormalities, using transmission electron microscopy, were noted in the CECs. Therefore, no significant structural changes were noted following ocular instillation of K-115 ophthalmic solution.

In conclusion, the morphological changes in CECs, following instillation with K-115 ophthalmic solution, were considered to be of minimal toxicological significance because; 1) noted changes were transient after instillation, and CECs recovered by $24 \mathrm{hr}$ after instillation, 2) no enhancement by repeated instillation was noted, 3) no appreciable changes were noted in the corneal thickness, or the number of CECs at $24 \mathrm{hr}$ after instillation, an index of the function of CECs, and 4) no significant structural changes were noted.

\section{ACKNOWLEDGMENTS}

The authors have no conflict of interest directly relevant to the content of this article. This study was funded by Kowa Company, Ltd., and was supported by Ina Research Inc., Japan. The authors gratefully thank 
Safety evaluation of morphological changes in the CECs

Jun Shimizu, Jun Hokibara, Yoshihiro Takei, Kyoko Sakura, Yoshihiro Takei, and Haruko Koizumi of Ina Research Inc. for their expert technical assistance.

Conflict of interest---- The authors declare that there is no conflict of interest.

\section{REFERENCES}

Bi, Y.L., Zhou, Q., DU, F., Wu, M.F., Xu, G.T. and Sui, G.Q. (2013): Regulation of functional corneal endothelial cells isolated from sphere colonies by Rho-associated protein kinase inhibitor. Exp. Ther. Med., 5, 433-437.

Bourne, W.M. and Mclaren, J.W. (2004): Clinical responses of the corneal endothelium. Exp. Eye Res., 78, 561-572.

Carbajal, J.M. and Schaeffer, R.C.Jr. (1999): RhoA inactivation enhances endothelial barrier function. Am. J. Physiol., 277, C955-964.

Dikstein, S. and Maurice, D.M. (1972): The active control of corneal hydration. Isr. J. Med. Sci., 8, 1523-1528.

Hatou, S., Yamada, M., Akune, Y., Mochizuki, H., Shiraishi, A.,
Joko, T., Nishida, T. and Tsubota, K. (2010): Role of insulin in regulation of $\mathrm{Na}^{+}-/ \mathrm{K}^{+}$-dependent ATPase activity and pump function in corneal endothelial cells. Invest. Ophthalmol. Vis. Sci., 51, 3935-3942.

Honjo, M., Tanihara, H., Inatani, M., Kido, N., Sawamura, T., Yue, B.Y., Narumiya, S. and Honda, Y. (2001): Effects of rho-associated protein kinase inhibitor Y-27632 on intraocular pressure and outflow facility. Invest. Ophthalmol. Vis. Sci., 42, 137-144.

Leung, T., Chen, X.Q., Manser, E. and Lim, L. (1996): The p160 RhoA-binding kinase ROK alpha is a member of a kinase family and is involved in the reorganization of the cytoskeleton. Mol. Cell Biol., 16, 5313-5327.

Nagayama, K. and Matsumoto, T. (2008): Contribution of actin filaments and microtubules to quasi-in situ tensile properties and internal force balance of cultured smooth muscle cells on a substrate. Am. J. Physiol. Cell Physiol., 295, C1569-1578.

Prasain, N. and Stevens, T. (2009): The actin cytoskeleton in endothelial cell phenotypes. Microvasc. Res., 77, 53-63.

Sumide, T., Nishida, K., Yamato, M., Ide, T., Hayashida, Y., Watanabe, K., Yang, J., Kohno, C., Kikuchi, A., Maeda, N., Watanabe, H., Okano, T. and Tano, Y. (2006): Functional human corneal endothelial cell sheets harvested from temperature-responsive culture surfaces. FASEB J., 20, 392-394. 